\title{
The World Wide Web and Active Learning in the International Relations Classroom
}

\author{
Lynn M. Kuzma, University of Southern Maine
}

$\mathrm{O}$ ver the last two years, the explosive growth of information technology has excited and engaged faculty and students alike. Instructors have readily applied these advances to their educational endeavors. Many include their email addresses on syllabi, supplement class discussions with Internet news groups (Bailey 1995; Bowers 1994), ${ }^{1}$ create virtual libraries for current events assignments (Frantzich 1995), and conduct computer-aided simulations. ${ }^{2}$ One need only read the recent issues of $P S$ or International Studies Notes to find examples of the diverse uses of information technology in the classroom. However, few studies have provided a clear link between the use of technology and student learning goals. This article relates my development of an instructional project using the World Wide Web (WWW) in an international relations (IR) class. It begins with a description of the web and examples of how it is used by international relations students and scholars. It then explains an instructional web project and outlines its contribution to active learning and the development of student's criticalthinking and problem-solving skills. It ends with advice to prospective adopters.

\section{The World Wide Web and International Relations}

The World Wide Web, designed to distribute information across the Internet in a system known as hypertext (visible links to other docu-

Lynn M. Kuzma is an assistant professor of political science at Southern Maine University, where she recently moved from North Dakota State University. Her research interests include U.S. foreign policy, public opinion, international relations theory, and instructional techniques using technology. ments), is not the Internet, although it has, along with email, become the most famous and popular Internet item. The web gives the Internet a pretty face. It does for the Internet what the Macintosh did for the personal computer-provides the technology needed to offer a navigable, attractive interface for the Internet's vast sea of resources, the same way that a toolbar on a word processor screen obscures the intimidating codes comprising the computer program.

The web's features make it a powerful tool for providing access to global information sources. Scholars and students of international relations, especially, will find much of interest on the web. For example, international organizations, most notably the United Nations (www.un.org), now publish their materials on the Internet. ${ }^{3}$ Using the web, researchers have instant access to documentation of important international events and agreements. 'This greatly benefits faculty and students whose university libraries are not UN document depositories.

Online information is current and often more complete than traditional information sources. It also quickly reflects the changing nature of international events. Many national and international newspapers are currently online. ${ }^{4}$ These can be valuable resources for IR classes preparing to discuss current events or, to give a specific example, allow a Model United Nations team representing India to have access to The Hindu, the leading Indian online newspaper (www.the-hindu.com). The web's international reach also permits users to locate opinions and perspectives from individuals across the US and around the world. Many from the international community readily post their work on the web. Everyday, more sources become available on- line as individuals and institutions discover the wonders of the web.

Given the boundless amount of information on the web and its publishing potential, one would expect a high level of use in college courses. According to a recent Campus Computing survey, however, using the web to support specific instructional objectives is running at only $6 \%$ (Green 1995; Geoghegan 1996, 30). This statistic has undoubtedly increased over the last two years, but has not expanded as rapidly as the web's potential. Are faculty having difficultly revising syllabi to incorporate technological innovations or are instructors not convinced of the web's instructional benefits (Postman 1995, 1996)?

To answer these questions, we must first assess how beneficial technology is to the education endeavor (Jordan and Sanchez 1994). Technology, after all, is not an outcome but an "enabling resource intended to supplement, enhance, and extend the learning experience" (Green 1996, 28). Educators should evaluate whether the prescribed technological tool advances learning objectives specified during course development. The experiences of innovators and early adopters, the names given to those who invest time and resources in the application of new technological advances (Rogers 1995), should provide guidance as others venture into new instructional terrain. With this in mind, I will relate my experiences while developing an international relations class project using the WWW.

\section{The Web Site Project}

In the fall semester of 1997, I incorporated a web site project into my Politics of Global Problems class at North Dakota State University. This upper-level, political science course examines various topics of 
concern to the global community, such as democratization, nuclear proliferation, ethnic and regional conflict, human rights, the environment, and development. Given the diversity of topics, twenty-five students from a variety of university departments were drawn to the class. Students' majors included pre-med, public administration, sociology, women studies, pre-law, environmental science, political science, and economics. This assortment prompted me to devise a research project that would capitalize upon the students' range of interests and expertise while utilizing advances in information technologies that could be beneficial for studying global issues.

Toward this end, each student was required to produce a final project in which they examined a class topic at length using an illustrative case. For example, students interested in women's studies devised a project that related women's experiences with human rights in India and the development process in Africa. Premed students examined problems associated with global immunization. Economics majors analyzed development issues in Russia and Mexico, while a future journalist and environmental scientist related the threats to the global environment posed by development.

This project sounds very similar to a typical group research paper, and it is. However, it differs in the type of medium used. Instead of requiring students to produce a written paper that the instructor would evaluate, the students were asked to create a web site on their chosen issue, complete with text, images, graphics, hypertext links, and an "annotated jumppage." 5 Each group was required to present their final project in a public forum. Links to students' completed projects are available on the course home page (www.ndsu.nodak.edu/instruct/ kuzma/global/webproject.htm).

\section{Web Project Challenges}

One of the key challenges of the web project was acquainting students with a software package that would write HTML code, the computer language used by web browsers. Thus, each student attended three one-hour computer sessions devoted to learning an HTML word processor. Until very recently, those interested in producing web pages had to know the raw HTML codes. This made publishing on the web less likely than having a scholarly piece accepted by the American Political Science Review. Today, however, there are many software packages to help even the computer novice create interesting web pages. ${ }^{6}$ In fact, the newest version of Netscape, Netscape Communicator, has a "composer" feature that writes HTML code.

Once the students got over their initial fear of using an unfamiliar word processing package, even those with computer phobia quickly became proficient at constructing rudimentary web pages complete with text and images. Students already well-versed in HTML (you will be surprise to learn how many students actually possess this skill) were quickly on their way to producing highly interactive web pages. For instance, students who studied nuclear proliferation created a web site complete with exploding bombs.

Before constructing their web pages, students were required to submit a flowchart, or story board, of their intended web site to the instructor. The flowchart is a useful way of diagraming how pages of the web site will link to each other and outside web pages. In essence, the flowchart is a non-linear outline of their research project. At the heart of the flowchart is the homepage where the reader gets a general idea of what is contained within the site and gains access to any desired part. The students were also asked to create a "Table of Contents" on their homepage to help explain the site's organization and structure.

Creating flowcharts proved difficult for the students, and I spent a good deal of time with them individually organizing their web sites. Students found this task challenging because of their familiarity with creating a term paper, which requires linear thinking-i.e. one paper element follows the next until the conclusion. Web sites, in contrast, demand three-dimensional representation. With practice, students became comfortable thinking of their homepages as a point in an intricate web of information. One student found the ability to create links between ideas in this way very liberating. He stated, "I was able to add important information to my web site. I would have had to leave out the same information if writing a traditional term paper because it, although important, was not directly relevant to my thesis. It did not follow a specific train of thought, but was much more important than a simple footnote. I was glad I got to include it in my web project."

After the computer introduction and the initial stage of web site layout, some time was spent on web page design considerations such as choosing font size, screen width, colors, graphics, and backgrounds. The instruction for this was done by a computer consultant at North Dakota State University and final choices rested upon individual authors' senses of aesthetics. However, guides to web design are readily available both online and in web word processing packages available at local software stores. ${ }^{7}$ Armed with the basics, the students were ready to produce their own web sites.

\section{The Web and Active Learning}

The ability to think clearly and critically, ${ }^{8}$ to effectively solve problems, ${ }^{9}$ and to construct knowledge are cognitive goals of education (Bransford et al. 1987; Ennis 1987, 10). However, the traditional "instructional model," where the teacher lectures to students, creates an authoritative didactic that instills passivity in students and invites unquestioning acceptance (Mather 1996). Many educators have rejected this model and have adopted teaching methods that encourage students to become "active" learners. They call for a learning model in which students and teachers work together 
in an active learning environment (Barr and Tagg 1995). How does technology fit into this new learning model?

It is vital that technology is not viewed as an end in itself, but is used as a means toward reaching active learning educational goals. Given its communication and publication abilities, the web is an educational tool that is uniquely suited to advance student-centered learning and develop student's cognitive skills. By making vast amounts of resources highly accessible, it allows learners to become skilled at evaluating and integrating information, which, in turn, enhances their critical thinking abilities. By providing a publication outlet, it enables students to create knowledge, not just accumulate facts. By serving as a presentation medium, it facilitates the development of students' problem-solving skills.

\section{Evaluating and Integrating Knowledge}

There is no doubt about it, we live in an information age. Students and teachers have their hands full trying to cope with the overwhelming abun-

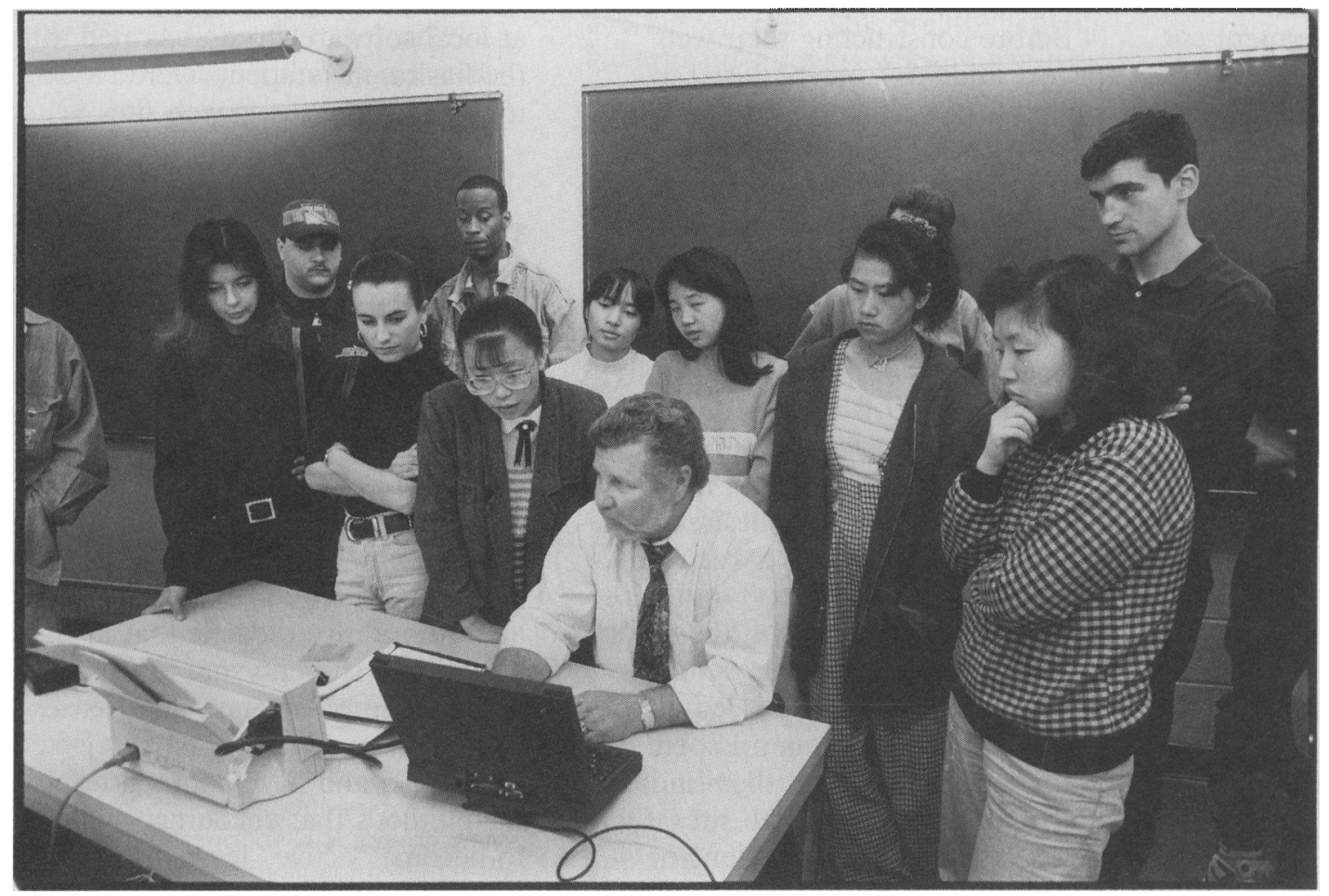

Photo courtesy of Rutgers University dance of information. This can be a blessing or a curse. If information is power, we are positioned for greater personal development than ever before. The web opens new information avenues allowing multitudes to consume and cre-

ate knowledge.

However, this utopian view of the web's potential is readily questioned by anyone who has spent time on the Internet. At issue is the available information's relevance and quality. Critics of the web worry that information glut may pose an even greater challenge than information scarcity ever did (Postman 1996).

They claim that technology has outpaced our ability to create standards and guidelines. For instance, information on the web can include vanity postings, advertising, and scholarly/specific

\section{teachers work to- gether in an active learning environment.}

sources. Vanity publishing is documentation that has not been through the peer review process or disseminated by the trade publishing industry. Since anyone can publish on the web, many resources are not verified by editors or fact checkers. The Internet allows a whole new group to enter the world of publishing, specifically "those who didn't learn the culture of the print publishing trade" (Tillman 1996).

To make matters worse, the goals or aims of some persons or groups presenting material on the web are not clearly stated. As some have pointed out, the web often functions as a "virtual soapbox" (Alexander and Tate 1996). The list of problems grows. Dates are not included on sites. It is hard to determine the extent of web coverage and when one site begins and another ends. There is no clear distinction between advertising and information. Search engines, such as Yahoo, can retrieve web pages out of context. Web pages can move or disappear without notice, making searches frustrating for students and scholars alike. Overall, web pages are not stable entities. In fact, a good computer hacker can enter most and alter their content at will. These characteristics allow one to compare the web to the The Wild West, a place where anything (and everything) goes.

For these reasons, one can understand 
why many educators would be skeptical of using the web as an educational tool. They may believe students are less capable of coping with the complexity inherent in the web because they do not have the analytical frameworks for sorting things out. They also worry that students will be overwhelmed with information, led astray by biased sources, and mistake fiction for fact. However, those who contend that the web provides too much information to students need to separate information delivery and instructional questions. Learning is affected more by what is delivered, and by the receiver's ability to interpret it, than by the delivery medium.

What educators are now realizing is that we should teach our students new thinking skills, ones that allow them to select from among a varied array of information so they do not get bogged down in the selection stage of problem solving (Pellegrino $1995,12)$. Included with this is a call for introducing students to effective strategies for sorting and using problem-relevant information. As Mather (1996) states, "A common goal is to create self-directed life-long learners who are well-equipped for productive roles in society. Our society is rapidly becoming an informationdriven one, and so it is incumbent upon us to equip students of the future to be effective information managers."

Currently, however, the "instructional approach" to education, combined with the use of textbooks, favors the largely uncritical acceptance of information by students. The teacher or librarian decides whether the material is appropriate, not the student. Students are robbed of the chance to critically evaluate the material on their own and thus, become passive acceptors of what is presented to them. What is needed is for instructors to develop students' "critical literacy" (Jongsma 1991; Mann 1994; Farah 1995). Students must become information managers, knowing how to access, organize, and present information, not information regurgitaters.

The web provides an avenue to help us develop our students' critical literacy. Confronted by the expansive resources of the Internet, students will learn how to manage information by mastering evaluation skills. Students will decide if the web pages they encounter are accurate, current, or/and biased, and whether there is a clear authority and complete coverage (Alexander and Tate 1995). ${ }^{10}$ One of the goals of the web project was to have students practice evaluating web resources. For instance, requiring students to include an "annotated jumppage" on their final web sites served dual purposes. As a directional tool, it helps readers assess information on related web sites. As an evaluation tool, it gave the students practice in assessing and integrating information found on the web. Overall, each student was required to give a written assessment of each web site they used or linked to their projects. ${ }^{11}$

The students' performance on this evaluation and integration task was mixed. Many were more fascinated by the "cool" sites they foundthose with interesting graphics-than those rich in content. Often, their choices of links to other web sites were based on surface considerations rather than substance. This was not universally the case. Some projects exceeded the instructor's expectations. Without having to be led by the hand, many found the most topically relevant sites on the Internet. Naturally, the United Nations proved the most popular link, but some very exciting and informative sites were uncovered and presented in very innovative ways. In the future, more time will be focused on teaching students web-evaluation criteria. Also, a more formal class requirement concerning web site evaluation will be adopted.

\section{Creating Knowledge}

In the instructional approach to education, the typical means of expression is linguistic. The teacher stands in front of students and slips his or her own mental constructs into the minds of students in the form of metaphors, equations, and, maybe, a few line drawings. Students use them as building blocks to recreate the construct (Fraser 1996). In contrast, active learning occurs when multimedia tools, like the web, are used to present students with complex situations and problems with information embedded in multiple representational forms. This encourages students to use numerous and varied representational strategies and explore new ways of thinking, switching back and forth from linguistic to visual (Pellegrino 1995, 12).

The web project described here allowed students to create hypertext as supplemental information to the main text of their web site. Students were able to add audio and video inputs, images, animated sequences, or any of these in combination. As a user of hypermedia, the student chose what to do next. As the creator of these products, the student decided what information to make available to the audience (Mann 1994, 174). They became creators of knowledge.

Students enjoyed linking graphics with text and felt that they were "better communicators" when they introduced multimedia elements to their web sites. (Most focused on adding images to the text, none, however, took advantage of sound additions.) Those more technologically advancéd included some animation. Overall, the students got a taste of how different representations can enhance the exchange of ideas.

It has been assumed that because computers and the web are relatively new additions to the educational environment and expectations and objectives for their use are incomplete, students will be prompted to "form their own objectives and become empowered not only by the new media, but also by the lack of limitations placed on them by instructors" (Mann 1994,175). My hope for the web project was that this liberation would allow students to become more creative and uninhibited in their production of knowledge. However, this was not the case in the Politics of Global Problems class. The biggest complaint the students had about the web project was that it was too open-ended; many stu- 
dents reported that they were very intimidated. This feeling did not go away as the students became familiar with the HTML word processor and the Internet. The students wanted more structure, more specifics. Many were uncomfortable with the fact that they were "flying by the seat of their pants." One student said, "You have to crawl before you can walk." Instead of being amazed at the possibilities open to them, the students were more concerned about the instructor's expectations of very germane items such as "How many (web) pages does it have to be?" "What do three web pages convert to in terms of a research paper?" "How many images do I need?" "You won't mark my project down if I do not have all these fancy graphics, will you?" These responses are understandable. Most instructors hear them when giving any assignment. It was disappointing, however, to hear them in relation to a project that was intended to liberate students from the usual constraints and expectations of a term paper.

The success of the project came when students saw their completed web sites on the Internet for the first time. They were amazed at what they had accomplished. But, at the same time, they had the realization that if they could publish on the web so could anyone else. This produced a healthy suspicion on their part. One stated, "If I can do this then that means that anyone else can too. We should not automatically accept what someone else has put on the web." This taught the students an important lesson: not everything they read on the web is accurate or worthwhile. Hopefully, these critical thinking and evaluation skills will transfer to their use of other information sources as well.

\section{Communicating Knowledge}

We increase the likelihood that critical thinking and effective problem solving will occur when students learn to explain their representations and goal choices to an audience. This happens during class discussion when students defend their position on an issue or when they write term papers. During these exercises they often notice something different they had not previously considered. The communication stage is crucial to helping students become successful problem solvers. As one educator notes, "It is only when we have our students attempt to express their thoughts and ideas to others, through language or other symbolic media, that they come to realize the flaws in their logic" (Pellegrino 1995, 11). By requiring students to make their thinking "visible" to others as well as to themselves we foster their problem-solving abilities. Students learn to focus their thoughts, revise tests, and produce quality work.

The web project "made visible" to the world the students' thinking. By being published on the web, the students' projects were literally available to any interested party. One student noted, "Even though I was very skeptical about the web project I found it to be very useful in the end. I learned a lot more while doing this project than most term papers because I was concerned about the large number of people who could possibly see my project. I had to really think things through." Another stated, "It helped to learn a new way of presenting information instead of just having a few sheets of paper. I ended up with something anyone can look at, not just the instructor." In fact, students have received emails from individuals all over the world who read their web sties and wanted to share their reactions.

Presenting their work on the web had additional benefits for the students. Because the students were allowed to choose topics that were germane to their majors, their web projects could be used as examples of prior work that was relevant to their future career goals. A woman interested in applying to the Peace Corps and serving in Africa, for example, listed her "Women in Development" URL on her application. Another student, in pre-med, was able to link his web site on "Global Immunization" to his biochemistry instructor's research. Others included their web site addresses on applications to graduate schools, law schools, and in cover letters to potential employers.

Overall, the web project was a successful application of information technology to an instructional setting. As a tool, the web allowed the students to research the vast resources of the Internet, improve their evaluation skills, create an informative product of their own, and communicate their work to a world audience. This project, in sum, helped students develop criticalthinking and problem-solving abilities.

\section{Warnings for Potential Web Project Adopters}

Although I would definitely rate the web project a success, I feel I should offer some words of caution to prospective adopters. First, be prepared to invest an incredible amount of time prior to, at the beginning, and during the uploading phase of the web project. If one is not already proficient in web publishing and using file transfer protocols, much time is required to develop these proficiencies. I gained experience attending seminars on the topic and constructing web sites for different courses. One can get by using the same web publishing software as the students. It is a good idea, however, to learn more about HTML coding so you will be able to help students with their web construction problems and any difficulties that may arise when uploading the pages from the desktop to the web server. In this regard, the project was far more complex and time consuming than I originally anticipated. But, having issued this warning, I will also give you the same line I give my students when they complained about having to learn to publish on the web: "The future is now. You will have to learn to publish on the web someday, why not now?"

Second, sustained investment of personnel (faculty and technical support) and financial resources are necessary for students to develop web sites. Green (1996) observes that infrastructure fosters innovation. For instance, the use of email ex- 
panded once-local-area-network desktop machines to the Internet. As one scholar warns, "It may seem an easy matter to add an email address or web-based assignment to your syllabus, but it makes sense to do so only if the instructor-and the student-have easy access to a network providing the necessary tools" (Johnson 1996, 31). One of the reasons I developed and incorporated the web project was because support was available at North Dakota State University in terms of hardware, software, and personnel. Students had access to computers and scanners at almost anytime of the day or night. The needed software packages were available at no additional cost to the students. Knowledgeable personnel were available to answer the students' and instructor's questions during the hours the computer center was open. Educators interested in developing a web project should deter-

\section{Notes}

1. See Klass (1995) on how to create Internet discussion groups in class.

2. The ICON (International Communication and Negotiation Simulation) program, administered by the department of government and politics at the University of Maryland, is a computer-aided international negotiation summit. It is also an excellent example of how the Internet can be used for better pedagogy. See Vavrina (1992, 1995), Starkey and Wilkenfeld (1996), and Crookall and Wilkenfeld (1985). See also Caldwell (1991).

3. For a web site that does an excellent job of organizing Internet resources related to the United Nations, see the UN Scholars' Workstation at Yale University (www.library.yale.edu/ un/).

4. For example, the New York Times can be found at www.nytimes.com. mine the availability of these resources at their college or university. Given the amount of administrative pressure to incorporate technology in our teaching, many will find an abundance of these resources available and just waiting for you to take the initiative.

Lastly, given the amount of time it takes to learn new technologies and devise appropriate instructional projects that use them, it is vital that the faculty's institution rewards courseware development. In the past, many would not devote valuable time to teaching endeavors that did not put them in good stead when it came time for tenure or promotion. In many academic institutions, there was no incentive to excel in teaching. Slowly but surely this is changing, although each institution varies in the importance it places on teaching. It is up to the individual faculty member to decide for him or herself whether the rewards of introducing new technologies in the classroom justifies his or her time commitment.

\section{Conclusion}

Will the web become a "core tool" of academe? It is hard to say. Overall, curriculum enhancement and innovation using the web will remain largely dependent on the interaction between individual initiative (the way faculty design their syllabus and structure their classes to include web projects) and institutional infrastructure (hardware, software, and support services). As technological advances facilitate web publishing and institutions reward instructors who invest their time in course development, we will see an increase in instructional projects that include the WWW.
5. An annotated jumppage is a summary hypertext page where other Internet sources are linked to the student's web site. It is annotated so that viewers have an idea of the contents of the linked site before visiting it.

6. Microsoft Frontpage, Claris Homepage, Hot Dog, and Adobe PageMill are a few.

7. A condensed source and examples of "dos" and "don'ts" can be found online at Web Pages That Suck (www.webpagesthatsuck.com).

8. Critical thinking is defined as the "reasonable reflective thinking that is focused on deciding what to believe or do" (Ennis 1987, 10).

9. The ideal problem solver, according to Bransford et al. (1987), emphasizes five components of thinking: 1) identify problems, 2) define and represent them with precision, 3 ) explore possible strategies, 4) act on these strategies, and 5) look at the effects.

10. A workshop entitled "Teaching Students to Think Critically about Internet Resources" hosted by University of Washington C\&C/ UWired Computer Training is available online (http://weber.u.washinton.edu/ libr560/

NETEVAL/index.html). Checklists to help students recognize the difference between informational, advocacy, and business pages are available online (www.science.widener.edu/ $\sim$ withers/inform.htm).

11. The web site evaluation worksheet that the students used was adapted from "Evaluating Web Sites On the Internet" (http://milton.mse. jhu.edu:8001/research/education/net.html).

\section{References}

Alexander, Jan, and Marsha Tate. 1996. "The Web as a Research Tool: Evaluation Techniques." (Available online: www.science. widener.edu/ withers/evalout.htm).

Bailey, Martha. 1995. "USENET Discussion Groups in Political Science Courses:" PS: Political Science and Politics 28(4): 721-22.

Barr, Robert B., and John Tagg. 1995. "From Teaching to Learning - A New Paradigm for Undergraduate Education." Change 6(March-April): 13-25.

Bowers, David Alexander. 1994. "Using Prodigy and Other Online Services in the Political Science Classroom." PS: Political Science and Politics 27(4): 708-12.

Bransford, John D., Robert Sherwood, and Tom Sturdevant. 1987. "Teaching Thinking and Problem Solving." In Teaching Thinking Skills: Theory and Practice, ed. Joan Boykoff Baron and Robert J. Sternberg. New York: W. H. Freeman and Company.

Caldwell, Daniel. 1991. "The 1990 Middle East Crisis: A Role Playing Simulation." Foreign Policy Analysis Notes 16(2): 13-15.
Crookall, David, and Jonathan Wilkenfeld. 1985. "ICONS: Communications Technologies and International Relations." System 13(3): 25358.

Ennis, Robert H. 1987. "A Taxonomy of Critical Thinking Dispositions and Abilities." In Teaching Thinking Skills: Theory and Practice, ed. Joan Boykoff Baron and Robert J. Sternberg. New York: W. H. Freeman and Company.

Farah, Barbara D. 1995. "Information Literacy: Retooling Evaluation Skills in the Electronic 
Information Environment." Joumal of Educational Technology Systems 24(2): 127-33.

Frantzich, Stephen. 1995. "Press Briefings Exercise." PS: Political Science and Politics 28(4): 728-30.

Fraser, Alistair B. 1996. "The Web, a Classroom Sans Walls." Syllabus 10(4): 18-20.

Geoghegan, William. 1996. "In Response To Kenneth Green." Change 7(March-April): 30.

Green, Kenneth. 1995. "The 1995 National Survey of Desktop Computing in Higher Education. (Available online: http://ericir.syr.edu/ Projects/Campus_computing/index.html).

- . 1996. "The Coming Ubiquity of Information Technology." Change 7(March-Aprik): $26-28$.

Johnson, Larry. 1996. "In Response To Kenneth Green." Change 7(Mar.-Apr.): 31.

Jongsma, Kathleen Stumpf. 1991. "Critical Literacy." The Reading Teacher 44(7): 518-19.

Jordan, Donald L., and Peter M. Sanchez. 1994. "Traditional Versus Technology-Aided In- struction: The Effects of Visual Stimulus in the Classroom." PS: Political Science and Politics 27(1): 64-67.

Klass, Gary M. 1995. "Bringing the World into the Classroom: POS302L-The Race and Ethnicity Seminar Discussion List." PS: Political Science and Politics 28(4): 723-25.

Mann, Christine. 1994. "New Technologies and Gifted Education." Roeper Review 16(3): 172-76.

Mather, Paul, 1996. “Critical Literacy: The WWW's Great Potential." (Available online: http:/ei.cs.vt.edu/\%7Ewwwbtb/book/chap6/ critical.html)

Pellegrino, James W. 1995. "Technology in Support of Critical Thinking." Teaching of Psychology 22(1): 11-12.

Postman, Neil. 1995. "Virtual Students, Digital Classroom." The Nation, October 9, 377-82.

- 1996. "When it Comes to Technology ... The Postman Always Thinks Twice." School Library Joumal (May):18-11.
Randall, Neil. 1995. "The World Wide Web: Interface on the Internet." Discover the World Wide Web. Indianapolis: Macmillan Computer Publishing.

Rogers, Everett M. 1995. Diffusion of Innovation, 4th ed. New York: The Free Press.

Starkey Bridgid, and Jonathan Wilkenfeld, 1996. "Project ICONS: Computer-Assisted Negotiations for the IR Classroom." Internaitonal Studies Notes 21(1): 25-29.

Tillman, Hope N. 1997. "Evaluating Quality on the Net." (Available online: www.tiac.net/ users/hope/findqual.html).

Vavrina, Vernon J. 1992. "From Poughkeepsie to Peoria to the Persian Gulf: A Novice's ICONS Odyssey." PS: Political Science and Politics 28(4): 700-02.

-. 1995. "Poughkeepsie to Persian Gulf Revisited: ICONS, The Internet and Teaching International Politics." PS: Political Science and Politics 25(4): 725-27.

\section{United States Institute of Peace 1999 Solicited Grant Competition}

The United States Institute of Peace Grant Program is pleased to announce the 1999 Solicited Grant Competition.

\section{Topics AND THEMES}

Solicitation A: Bosnia and the Balkan Region

Solicitation B: The Middle East

Solicitation C: Training in Conflict Management

Solicitation D: The Changing Nature of Diplomacy

\section{Deaduine for Applications}

The closing date for receipt of solicited grant applications is January 4, 1999. Notification of awards will be made in April.

\section{Addrional Information and Application Materials}

Contact the United States Institute of Peace $*$ Grant Program $*$ Solicited Grants

1550 M Street NW * Suite $700 *$ Washington, DC 20005-1708

(202) 457-1700 * Fax (202) 429-6063 * TTY (202) 457-1719

e-mail: grant_program@usip.org or visit our web site at www.usip.org/grants/sg99.html

Note: As of Nov. 1, 1998, the Institute's address will be 1200 17th Street NW, Washington, DC 20036-3006. 